\title{
As múltiplas vozes na constituição de $K$. : relato de uma busca, de Bernardo Kucinski
}

Thiago Sampaio Pacheco*

O romance K.: relato de uma busca, desde sua publicação, em 2011, tem se destacado no panorama da literatura brasileira contemporânea. Publicada primeiramente pela Expressão Popular, a narrativa marca a estreia literária de Bernardo Kucinski, jornalista e professor aposentado da Universidade de São Paulo. Tendo participado de concursos literários, o romance figurou entre os finalistas dos Prêmios São Paulo de Literatura, União Brasileira de Escritores e Portugal Telecom. Após essa breve apresentação, informamos que o objetivo deste artigo é analisar as múltiplas vozes narrativas constitutivas da obra K.: relato de uma busca (2016), sem deixar de considerar seu nítido diálogo com a história, na tentativa de retomar e reelaborar acontecimentos passados e sua repercussão no presente. Buscamos analisar o romance de forma imanente, utilizando-nos do método materialista histórico-dialético. A nossa intenção é, portanto, investigar as especificidades dos narradores desse romance em sua estreita relação com a forma social, conciliando fenômeno literário e interpretação político-histórica.

\section{As fronteiras entre a história e a ficção}

Para compreender a relação entre história e ficção sob a perspectiva da crítica literária dialética, Lukács (2011) recupera a

\footnotetext{
*Mestre em Estudos Literários pela Universidade Federal de Goiás (UFG).
} 
noção de fábula aristotélica ao dizer que o tempo é uma categoria inerente da forma romanesca, pois literatura e história estão entranhadas indissoluvelmente. História é fábula humana em forma social e fábula é história condensada em forma literária. Ambas são formas que estão ligadas dialeticamente.

A literatura, maneira artística peculiar de vivenciar o mundo, reflete esteticamente a vida. Há uma reposição estrutural da matéria social em forma estética. Possuindo regras próprias, a literatura só pode existir enquanto criação e fabulação da realidade. Nesse sentido, na teorização sobre romances que possuem um nítido diálogo com a história, Lukács em $O$ romance histórico afirma que a história não deve se colocar como roupagem, mero cenário temporal do enredo romanesco. A verdade histórica implicada na forma romanesca deve configurar-se na particularidade humana, na especificidade histórica de seu tempo.

Em pleno século XXI, como se sabe, não é novidade a literatura que se alimenta do discurso histórico. Os romances brasileiros com pano de fundo histórico que surgem nesse período dialogam com a tradição dos romances das últimas décadas do século XX -- período em que a narrativa se debruçava, entre outras coisas, sobre a tarefa de questionar a história do golpe de 1964, contribuindo para forjar a tradição historiográfica da ditadura militar no Brasil. A publicação de narrativas que mantêm um diálogo estreito com a história não pode ser considerada acidental. Esses prosadores buscam, seja na pesquisa histórica ou na experiência vivida, inserir em suas produções literárias aquilo que a historiografia, circunscrita em seus limites, não pode oferecer: a compreensão de um movimento mais amplo e complexo da vida. Nessa tentativa, as letras proporcionam, por meio da consciência particular, o acesso à totalidade do movimen- 
to da história. É exatamente por existir como um todo articulado em outro tempo e espaço que a obra ficcional de Kucinski, em um duplo movimento de afastamento e aproximação da vida, consegue reconfigurar formalmente o mundo. Seu romance aborda um mundo inventado para ampliar e enriquecer o próprio real, aquela realidade histórica de 1964. Para Eurídice Figueiredo, a literatura, ao contrário até mesmo do mais fiel registro documental, consegue recriar "a dor e o sangue, as lágrimas e as feridas que se abriram no corpo da Nação e na lembrança traumática dos sobreviventes" (2017, 44). A literatura é a modalidade discursiva capaz de mobilizar o pathos, de cumprir "um papel de suplência em relação à historiografia [...], conseguindo nos entregar aquela verdade nefanda e inter-dita que o relato ou a crônica dos acontecimentos não podem e, talvez, não devem dizer" (Finazzi-Agrò: 2014, 182).

Parece-nos, assim, que Bernardo Kucinski em K.: relato de uma busca se utiliza do discurso ficcional para dizer de uma dor que não "cabe" nos limites do discurso jornalístico e/ou histórico. Em um jogo entre realidade e ficção, o autor adverte o leitor antes que comece a leitura: "Caro leitor: tudo neste livro é invenção, mas quase tudo aconteceu" (2016, 11). Portanto, as estratégias narrativas empregadas na obra elucidam a intensa função humanizadora e transformadora proporcionada pela literatura, possível aqui, especificamente, por meio de uma estrutura lacunar e inacabada, própria das tendências estéticas dos romances contemporâneos. Essa estrutura traduz a impossibilidade de darmos conta de maneira definitiva da História. Por essa razão, apenas dimensionamos seus fragmentos, pois a História não está totalmente circunscrita na narrativa, mas a usa como ferramenta para ampliar 
sua dimensão de compreensão e tornar-se, no mínimo, um símbolo de resistência ao apagamento ou ocultamento dos sujeitos que sucumbiram ao regime ditatorial, transformando-se no testemunho de um período terrível de nossa história que não pode ser narrado pelo detentor do pau de arara.

\section{Estética do fragmento e múltiplas vozes em contexto ditatorial}

Há, no romance de Kucinski, a reunião de diferentes vozes na tentativa de representar sujeitos de uma história, a do contexto da ditadura militar. Em outros termos, a narrativa conta com uma multiplicidade de enunciadores que, de uma forma ou de outra, se ligam à narrativa central, que é a busca de K. pela filha desaparecida em função do regime ditatorial. Segundo Caetano, tal estrutura heterogênea, em que diferentes vozes e gêneros textuais se intercalam, "aponta para uma fragmentação do real, o qual busca ser apreendido por discursos distintos" $(2015,78)$. O romance é construído sob uma espécie de estética do fragmento, uma vez que tanto o autoritarismo quanto a dor do pai que nunca se aplacará são inseridos em um mundo do qual somente parecem restar incertezas e contradições justapostas.

Vemos essa representação do mundo em "As cartas à destinatária inexistente" e em "Post Scriptum", fragmentos do romance enunciados em primeira pessoa pelo irmão da desaparecida (identificada pela inicial A). Esses fragmentos trazem, ao fim, a data de 31 de dezembro de 2010. Datados de mais de trinta anos após os eventos que serão narrados, tais trechos emolduram a narrativa. Esse narrador-autor se coloca, ao mesmo tempo, dentro e fora do narrado, pois já está distanciado temporalmente dos fatos, bem como 
já antecipa ao leitor o desfecho da busca. Sua voz realiza uma espécie de balanço dos eventos, cuja memória é reativada pelo recebimento de cartas endereçadas à irmã desaparecida. No primeiro capítulo, o irmão de A. comenta sobre essas cartas:

O nome no envelope selado e carimbado [...] será o registro tipográfico não de um lapso ou falha do computador, e sim de um mal de Alzheimer nacional. Sim, a permanência do seu nome no rol dos vivos será, paradoxalmente, produto do esquecimento coletivo do rol dos mortos (Kucinski: 2016, 15).

A essa reflexão, em que o passado assume o centro da melancolia de seu emissor, mistura-se um sufocante sentimento de injustiça. Ele pensa sobre o intento de um governo que ainda tenta "arquivar os fatos", ocultar as verdades de um corpo morto que "foi desaparecido". A memória do trauma, portanto, é constantemente presentificada pelo envio das cartas, e a vida que tenta seguir, manca, quase em frangalhos, é desassossegada. Essa situação se transforma em uma estratégia da negação histórica: a manutenção do nome de A. no rol dos vivos, por meio das cartas, é não admitir sua morte.

Como afirmado anteriormente, o romance é estruturado a partir da perspectiva de múltiplas vozes. Já no segundo fragmento, intitulado "Sumidouro de pessoas", temos um narrador em terceira pessoa cuja focalização recai sobre K. É este o narrador predominante. Em outros capítulos, há uma enunciação em terceira pessoa que recai sobre outras personagens, como um casal de guerrilheiros em "A queda do ponto". O discurso de A. também se faz presente por meio de uma carta, que compõe o fragmento "Carta a uma amiga". 
Em "A cadela", temos a narrativa de um militar; em "A abertura", quem narra é o famigerado delegado Fleury ${ }^{1}$. Ainda há outras vozes enunciadoras presentes nos demais fragmentos, e todas acabam por se organizar à maneira de um mosaico, cuja figura final é imprecisa por conter lacunas impossíveis de serem preenchidas, sendo a maior delas, provavelmente, o que aconteceu de fato com A. e seu marido.

Portanto, entendemos que um sentido concreto possível para a presença das múltiplas vozes enunciativas é o de constituir um relato que dê a ver o período ditatorial no Brasil de várias perspectivas "de dentro", bem como apresente visões posteriores. Como já mostrado, há uma voz predominante, que é a que acompanha o protagonista K. Diversas outras vozes, que gradualmente se elevam por meio de gêneros textuais diversos, como carta, diálogo, relato, entrevista, memória e informe, se alternam ao longo da narrativa. Há, portanto, uma dissonância entre elas que se articula na esfera do ambiente privado, possibilitando entrever no discurso histórico a realidade cotidiana do episódio ditatorial iniciado em 1964. Nesse sentido, os objetos e encontros que aparecem no romance, bem como as ações das personagens que se encontram com K., convergem para questionar ou conformar o conjunto de impressões e de impulsos investigativos de K. para a conclusão do mistério sobre sua filha.

A narrativa de fato se inicia quando, em uma determinada manhã de domingo, K. sente pela primeira vez a pungência da História:

A tragédia já avançara inexorável quando, naquela manhã

\footnotetext{
${ }^{1}$ O delegado Fleury era vinculado ao Departamento de Ordem Política e Social (DOPS). É conhecido, entre outras coisas, por ter liderado o "Esquadrão da Morte", com a promessa de matar dez bandidos a cada policial morto em confrontos da época (Gaspari: 2014, 319).
} 
de domingo, K. sentiu pela primeira vez a angústia que logo o tomaria por completo. Há dez dias a filha não telefona. [...] E como não perceber o tumulto dos novos tempos, ele, escolado em política? (Kucinski: 2016, 16).

Geralmente, como observa Lukács no conjunto de seu pensamento, os autores de narrativas que promovem vínculos entre história e ficção se valem de eventos localizados na realidade, buscando criar um sentido conciliador entre sua criação fictícia e o elemento factual, que se tornará matéria fundamental daquilo que concebemos como arte. Essa assimilação se faz de modo explícito, pois parte da necessidade do autor de não só conhecer seu mundo, sua realidade circundante, mas também de fornecer as bases que ajudam a iluminar a história.

K. se dá conta de que decorreram dez dias desde o último telefonema de sua filha. Os rumores dos desaparecimentos de judeus, envolvendo a política e a ditadura, deixam-no inquieto. A frustração pelas respostas não obtidas na universidade em que sua filha trabalhava ativa sua memória e, com isso, "K. rememorou cenas recentes, o nervosismo da filha, suas evasivas, isso de chegar correndo e sair correndo, do endereço só em último caso" e com a recomendação de não passá-lo a ninguém. Atarantado, "deu-se conta da enormidade do autoengano em que vivera, ludibriado pela própria filha" (Kucinski: 2016, 19).

O narrador se aproxima intimamente de K. - conhece seus pensamentos e mistura sua voz à dele. A frustração não somente evoca a memória, mas também faz com que K. perceba atenta e detalhadamente a conjuntura das décadas finais do século XX no Brasil: “O Estado não tem rosto nem sentimentos, é opaco e perverso. 
Sua única fresta é a corrupção. Mas às vezes até essa se fecha por razões superiores. E então o Estado se torna maligno em dobro, pela crueldade e por ser intangível. Isso ele sabia muito bem" (Kucinski: 2016, 19).

A ditadura militar no Brasil, reflexo caricato do fascismo clássico, representou, na história da direita brasileira, uma animosa tentativa no sentido de dar continuidade à situação altamente privilegiada das forças conservadoras. Tais forças, ligadas às ideologias de direita em geral, representavam a existência e as exigências de forças sociais dedicadas a manter vantagens socioeconômicas que garantiam o estatuto de propriedade. Portanto, partindo desse pressuposto, os militares, seguindo na chave de Mussolini em 1914, se amparam no mito da pátria. "Brasil: ame-o ou deixe-o" era a fé, a paixão, a força motriz que alimentava o coração dos combatentes. Com isso, processava-se a exclusão social em troca da farsa do nacionalismo. O sentido social conservador dessa ideia era óbvio, pois criou um sentimento de coletividade que dizia que a pátria estava ameaçada pelo comunismo, dissimulando os capitalistas como beneficiários de um sistema explorador. A ditadura adotou a solução do agressivo pragmatismo radical: perseguição, sequestro, tortura e assassinato.

Esse "presente histórico" do romance é posto. K., por meio de suas rememorações como militante político na Polônia pré-Holocausto e da militância de sua filha junto à Ação Libertadora Nacional, percebe que há uma História e que ela interfere diretamente na vida tanto do povo quanto do indivíduo. Quando o narrador acompanha K. a uma reunião dos "familiares de desaparecidos políticos", percebe o conjunto de casos semelhantes acontecendo por todo o Brasil. Neste momento há referências à guerra de Canudos, à guerrilha do 
Araguaia. Quando K. ouve o relato de um senhor de Goiânia, cujos filhos "foram desaparecidos", toma consciência mais aguda das consequências advindas de sua conjuntura. K. percebe uma convergência assombrosa entre todos os casos: "as pessoas desapareciam sem deixar vestígios. Era como se volatilizassem" (Kucinski: 2016, 25). Ainda diante dessa constatação, suas experiências de trauma, que deveriam fazê-lo se reconhecer como massa que toma partido de sua condição enquanto ser histórico, na verdade operam outra função. No romance, o que une os indivíduos como massa não é o reconhecimento como agentes transformadores da história, mas como vítimas de um trauma coletivo.

Nesse jogo de contraposições entre as vozes narrativas, diversos são os narradores a que $\mathrm{K}$. não tem acesso, e de que apenas nós, leitores, tomamos conhecimento. A disposição dessas vozes tenta formar uma unidade para a apreensão do mundo, mas também se torna um emaranhado quando passamos à perspectiva de K. No terceiro fragmento, intitulado "A queda do ponto", o foco da narração em terceira pessoa recai sobre um casal de guerrilheiros que se encontra em desespero e pronto para seguir a única instrução na hipótese de um sequestro de um companheiro: o suicídio. Constatamos aí um narrador que se comporta de forma anacrônica, uma vez que mescla a angústia desse casal do passado ao presente de sua enunciação, que já é o período de redemocratização:

Numa sacola maior, de lona, despejam documentos arduamente elaborados de denúncia, os que consideram os mais valiosos. A lista dos duzentos e trinta e dois torturadores, que jamais serão punidos, mesmo décadas depois de fartamente divulgada, 
mesmo décadas após o fim da ditadura; os manifestos dos presos políticos, o dossiê das torturas, o relatório prometido à Anistia Internacional. E também a pasta de recortes de jornais sobre os hábitos e rotinas de empresários apoiadores dos centros de tortura. Não sabem que, exceto o já justiçado, todos eles morrerão de morte natural, rodeados de filhos, netos e amigos, homenageados seus nomes em placas de rua (Kucinski: 2016, 29; grifos nossos).

Observamos que as informações contidas nos trechos grifados (os torturadores impunes e ainda homenageados) só são possíveis para um tempo posterior ao presente do casal em fuga, mas o próprio casal já não tem convicção sobre a causa. Eles sentem que a "guerra está perdida", bem como "carregam passaportes falsificados de modo rudimentar e uma arma com cartuchos que talvez nem sejam adequados a ela" (p. 29). O narrador não faz questão alguma de separar os dois tempos, o que denota que a derrota dos militantes de esquerda era iminente e imaginada até mesmo por parte deles.

Esse narrador anacrônico retorna em outro momento, no fragmento intitulado "O matrimônio clandestino", quando K. se dá conta da vida dupla que levava sua filha. O pai se sente devastado, pois a filha se casa em segredo para ele, mas não para a família do marido. As perguntas de K., relativas ao relacionamento entre A. e o marido, "ficarão para sempre sem respostas. Nem se saberá com precisão, mesmo décadas depois, como foram sequestrados e mortos" (Kucinski: 2016, 42; grifo nosso). Novamente, a parte grifada só é possível para alguém que já pôde refletir sobre a matéria narrada 
depois de décadas.

A partir da perspectiva de Lukács em sua dialética com a teoria hegeliana, essas manifestações disjuntivas do narrador, feitas tanto no episódio do casal de guerrilheiros quanto no episódio da descoberta da vida oculta de A., representam moderadamente o anacronismo necessário para a representação da totalidade dos objetos que constituem e estruturam o período ditatorial representado no romance.

Os mecanismos expressivos da narrativa, sejam as memórias evocadas ou esse narrador que acompanha K. em sua frustrante busca, como tivemos a oportunidade de demonstrar até aqui, servem para reiterar essa contínua interação entre a vida social de seu protagonista com o mundo que o circunda, formando assim toda a base da atividade social desse mundo. E uma atividade que gradualmente se conforma nas páginas deste romance é a normatização da violência como processo permanente de solução política em momentos fundamentais de transformação histórica. Essa tendência se manifesta inicialmente no fragmento "Os informantes", por meio da presentificação da memória traumática de K., que recebe de seu advogado a notícia de que certo general irá recebê-lo a pedido da comunidade judaica do Rio de Janeiro. No Clube Militar, à medida que subia os degraus da escadaria, K. é tomado de assalto por seu passado em Varsóvia: “Alarmou-o a emergência da lembrança, que julgava soterrada sob os escombros da memória. K. tinha trinta anos quando foi arrastado pelas ruas de Wloclawek, acusado de subversão pela polícia polaca" (Kucinski: 2016, 37).

A direção e o movimento dessas rememorações se tornam visíveis em cada detalhe da jornada e da vida individual de K. Suas memórias são constantemente presentificadas sob a forma de um 
trauma que remete a uma vida envolvida com a militância política que foi emasculada por meio das atitudes repressivas e violentas de um governo autoritário. No entanto, essas rememorações não constituem a única forma de expressão da violência como processo de solução política. Vemos essa tendência se concretizar no romance, de maneira mais sutil, com o episódio, contido no capítulo "Nesse dia, a Terra parou", em que nosso protagonista assiste ao noticiário do Estadão em que o ministro da Justiça Armando Falcão revelaria o paradeiro dos desaparecidos. A notícia é mal relatada. Imediatamente nos damos conta disso, pois seu objetivo é ocultar a verdade do que aconteceu. Nesse momento, o peso da realidade basta. Kucinski tenta passar a figuração de um mundo real que não nos aparece completo; o traço fragmentário da notícia transmitida pelo ministro é experimentado como tentativa de autenticidade da História, certamente falseada. Os nomes ditos durante a transmissão, como nos comunica o narrador, não pertencem, sequer, a um único desaparecido político. A farsa atinge seu ápice quando é pronunciado o nome de um conhecido professor de economia que nunca desapareceu.

O pretenso "nacionalismo" da ditadura brasileira, por seu conteúdo classista e pelo modo como opera na prática, exige um jogo de manipulação das massas populares. Nessa dinâmica, limita brutalmente, por todas as vias, a participação ativa na luta política, impondo diretivas autoritárias. Essa valorização do mito da nação precisa ser agressiva, violenta; precisa recorrer a uma ênfase desumana para disfarçar o seu vazio, e com isso tende a desprezar e a falsear os valores de humanidade em geral. As massas passam a encontrar enormes dificuldades para seguir os caminhos das soluções coletivas. K. percebe isso ao tentar recorrer ao American Jewish Committee em Nova York, ao apelar para a Anistia Internacional em Londres ou à 
Cruz Vermelha em Genebra (como pode ser visto em "Jacobo, uma aparição"). Desse modo, as energias de K. encontram seu único refúgio e se dissipam pelos vários caminhos das "soluções" individuais.

A força do militarismo advinha, portanto, de seus poderes e domínios centralizados na cidade, estendendo-se às pessoas. $\mathrm{O}$ décimo capítulo, intitulado "A cadela", em que a voz é concedida a um dos sequestradores da filha e ao genro de K., ilustra bem essa força e o completo despreparo dos agentes. A voz dessa personagem, imersa em um monólogo interior, debate consigo mesma sobre a dificuldade em dar um fim a uma cadela, que em meio ao sequestro dos militantes acabou sendo levada também. A banalidade do assassinato toma proporção diante da apatia da personagem que é indiferente ao sequestro, mas se encontra completamente perturbada com a presença da cadela. A personagem chega a considerar que talvez os dois não fossem "terroristas" de fato. Afinal, o que fariam com uma cachorrinha assim? Tal atitude é uma consequência direta do pragmatismo radical perpetrado pela ditadura, servindo-se de mitos irracionais conciliados com práticas racionalista-formais de tipo antidemocrático. Este exemplo, de um nítido movimento chauvinista, pressupõe a preparação de um terreno reacionário que tenta constantemente, em meio à década de 70 no Brasil, minar as bases das forças que se insurgiam contra o governo militar.

A condição de proprietários dos meios de repressão social permitia aos militares desenvolverem uma situação de poder que lhes garantia a imposição de suas próprias decisões arbitrárias, o julgamento de causas e a aplicação de castigos conforme suas vontades e interesses políticos. Em virtude de tamanho poder, e ocupando o papel de chefe político, eles eram a fonte de coerção, decidindo sobre os destinos dos homens, fazendo valer a vontade 
individual em defesa do mito irracional da pátria e disseminando a falsa "demagogia" por meio da compra de informações de civis que espionavam uns aos outros. A ditadura militar logo percebeu que essas técnicas abriam novas possibilidades para a ação política e tratou de aproveitá-las. Esses valores imprimiam, certamente, aos militares as características de valentia e machismo, como podemos verificar de maneira pertinente a partir do surgimento de outra voz narrativa no enredo do romance.

No capítulo "Paixão, compaixão", temos o surgimento de uma nova narradora: advogada, amante do delegado Fleury ("ele"), também conhecido como "O terror dos comunistas". Em sua voz narrativa, a figura de Fleury encarna o "cabra-macho", o cangaceiro da metrópole. Macho brabo que manda matar e torturar qualquer um que ouse atravessar seu caminho, é muito bem definido pela voz narradora como: "sujeito cruel e sem escrúpulos, com poder de vida e morte sobre os outros" (Kucinski: 2016, 106). Não bastasse isso, Fleury também é figurado, através do discurso de sua amante, como o macho alfa que toma para si qualquer mulher que queira. A principal vantagem dessa "imagem" de violência e virilidade, difundida em larga escala, é que, ao mesmo tempo que disfarçava o conteúdo social conservador da ditadura militar, fixava a atenção da massa em uma espécie de "heróis da pátria" que estavam dispostos a fazer de tudo para proteger o Brasil do monstro do comunismo. Fleury, como relata sua amante, é: "Um homem tão poderoso, um pode-tudo" (p. 96).

Mais adiante, no capítulo "A terapia”, é retomada a narração em terceira pessoa, com foco narrativo em Jesuína Gonzaga, uma faxineira que trabalhava para o delegado Fleury na famosa Casa da Morte em Petrópolis, Rio de Janeiro. Em geral, no romance, os 
indivíduos sociais e solitários ganham o centro da narrativa para representar a coletividade. Em um romance como K.: relato de uma busca, no qual as fronteiras com a história estão abertas, há um princípio fundamental de que existe uma história e ela está intervindo diretamente na vida dos indivíduos. Dessa forma, para captar o engenho da realidade, é necessário fazer despertar as ações do cotidiano por meio de personagens típicos em situações típicas. Jesuína, portanto, encarna as singularidades essenciais para a expressão de uma tendência que perpassa a sociedade. Quando de sua representação, os destinos dos homens aparecem de maneira mais manifesta, entrelaçados às forças motrizes que impulsionam a conjuntura. $\mathrm{O}$ narrador, ao acompanhar e dar voz a uma faxineira, ex-detenta, que pode transitar nas diversas esferas daquele conturbado momento de disputa entre os militares e os militantes comunistas, se vale disso, pois relata e ilumina ao seu gosto o que foi a história da ditadura militar no Brasil. Dessa maneira, o que podemos perceber nesse momento do romance é a apresentação de uma voz socialmente silenciada, a de Jesuína, que, por meio da terapia, toma partido dos atos a serem narrados.

O delegado, para manter seu prestígio, principalmente junto àqueles que se punham contra o governo, promoveu uma série de ações que violentaram a democracia: subornou autoridades, falseou informações, alargou sua base de apoio por meio do financiamento de informantes e perseguiu, sequestrou, torturou e assassinou militantes de esquerda. Isso é relatado por Jesuína: "O Fleury chegava junto com o preso ou então logo depois; ele vinha de São Paulo, sabe, e na mesma noite ou de manhã interrogava, e depois os presos já sumiam, e dali uns dias vinham outros" (Kucinski: 2016, 118-9). Mais adiante, ela revela: “Os presos eram levados para lá [...] 
e nunca mais eu via eles [...] nunca vi nenhum deles sair. Nunca vi nenhum preso sair. Nunca." (p.123-4). Com isso, a força política do delegado era mantida, provocando o esfacelamento do poder e das lutas políticas promovidas pela esquerda. Esse mundo caracterizava-se por um conservadorismo, favoritismo e predomínio das elites reacionárias, cujos patrões (empresários e banqueiros) formaram oligarquias e detiveram a hegemonia política. Nessa dominação, em sentido mais abrangente, fundamentava-se o mito da pátria. Sendo assim, quem atentava contra essa ordem ou fosse contra os desígnios da nação era duramente punido, considerado subversivo e terrorista, pois sua ação significava o mesmo que se voltar contra a imagem do Brasil.

Esses exemplos sobre os militares e suas artimanhas aparecem dispostos ao longo do romance por meio das múltiplas vozes. Destas, merece nota o capítulo "O livro da vida militar", em que há o entrecruzamento do pensamento de um ex-general destituído do exército e a voz do narrador que age de maneira fragmentada e lacunar. Tal atravessamento discursivo surge para demonstrar como as relações de poder se organizavam naquele mundo que tenta ser constantemente reanimado em nossos dias de hoje. Por meio de um narrador crítico do militarismo é desvelado um mundo no qual os antepassados mandavam e desmandavam. Eram senhores dos destinos dos homens e cultuavam a violência e o machismo. Mais do que a violência e a barbárie como mecanismo de controle e exercício de poder, este narrador traz uma nova realidade: um sistema sujo, corrupto e favoritista que engole a si mesmo. Observemos um trecho:

Mas, como em toda organização burocrática, as regras só valem para legitimar o favoritismo imanente, nunca instau- 
rar a meritocracia. As amizades é que decidem. Os vínculos de lealdade. Não a lealdade leal, que não precisa razões para existir, é a lealdade calculista, necessária à sobrevivência na guerra interna pela promoção burocrática. Nesse exército de oportunistas as únicas batalhas são as travadas por cada um contra seu igual, na disputa pela promoção. As vagas minguando mais e mais à medida que se sobe a escala da patente (Kucinski: 2016, 131).

Esse sistema, uma espécie de neocoronelismo, herança do século XIX até meados de 1930, revela-se fundado na troca de favores. As promoções e as relações burocráticas, de forma geral, são tuteladas por aqueles que já se encontram avançados no esquema corrupto; somente assim se consegue a proteção. O sentimento de pertença é balizado pela bajulação e subserviência. É necessário agarrar-se ao saco de um militar para conseguir a promoção. Outra característica importante desse tipo de esquema é a traição: "A traição é o corolário da lealdade oportunista. Na corporação militar-burocrática, um oficial nunca se abre com outros dois ao mesmo tempo. Sempre a um só; assim, ao ser traído saberá quem o entregou" (Kucinski: 2016, 132). Por fim, aqueles que resistiam ou se opunham ao golpe eram expulsos. Dessa forma, as relações de contraposição entre os personagens, a sucessão progressiva de vozes e o paralelo entre as situações nos múltiplos focos narrativos aludem a este processo extremamente violento que foi o período dos Anos de Chumbo na década de 70 no Brasil.

Igualmente violentos foram os pactos de poder entre as classes dominantes, o alheamento político das massas e a legitimação deste período por meio das diversas instituições. Estilisticamente observa-se esta última questão figurada no rumor crescente do desapa- 
recimento da filha de K., professora de química, dentro da Universidade de São Paulo (USP). As universidades sempre ocuparam lugares pontuais nos projetos de ditadura. Isso porque, evidentemente, são responsáveis pela formação das elites intelectuais, principalmente as econômicas e políticas de um país. Além disso, são ambientes que reúnem uma grande quantidade de opositores que ousavam desafiar o regime, fossem eles alunos ou professores. É na radicalização da prática militar no ambiente universitário que deformações constitucionais como o AI-5 surgem. Tal ato institucional representava a tentativa de conter e eliminar os protestos estudantis e o ativismo político contra o golpe de ditadura. Mas isso não era o bastante. Para os militares era lucrativo não só criar os meios que pudessem conter o ativismo político, mas que pudessem ampliar a máquina reacionária do Estado de modo a vigiar e repreender as universidades ${ }^{2}$. Seguindo essa ideia, tais questões estão representadas no romance por meio do rumor crescente do desaparecimento da filha de K., em que os sujeitos inseridos dentro do ambiente acadêmico sofrem um embate: admitir a ditadura militar como uma realidade histórica e, desse modo, admitir que A. é de fato uma "desaparecida política", ou simplesmente acusá-la por “abandono de função”. Essa reunião deliberativa está inserida em "A reunião da Congregação".

No clamor da referida reunião, temos um narrador, em terceira pessoa, novamente anacrônico: "Este relato foi imaginado a partir da ata da reunião, transcrita nos trechos citados a seguir. Muitos anos depois, a reitoria anunciaria de público a injustiça da de-

\footnotetext{
${ }^{2}$ Em 1970, o governo militar colocou em funcionamento a chamada Assessoria de Segurança e Informação (ASI), que atuava no interior das instituições universitárias, subordinadas aos reitores. Os principais objetivos eram a vigilância e a coleta de informações de professores que pudessem atuar contra o regime ditatorial.
} 
missão da professora. Mas nunca admoestou nenhum dos envolvidos" (Kucinski: 2016, 142; grifos nossos). O narrador, em meio a uma cena de tensão, age como uma espécie de intermediador ao tentar iluminar os discursos que surgem transformados em palavras de ordem, que atentam contra a dignidade da professora e que, praticamente, legitimam o regime autoritário, enquanto outras vozes se silenciam em face do medo da perseguição. Nesse suceder de vozes que lamentam, se queixam, clamam e brigam, torna-se evidente a incompreensão dos homens com relação ao significado da ditadura militar. Em suma, observa-se o deslocamento da violência como uma espécie de fantasmagoria permanente que marca a passagem de uma ordem para outra, a transformação de um mundo centrado na democracia para outro nitidamente pautado na eliminação das liberdades individuais, e, principalmente, a mudança nos mecanismos de repressão e controle das vozes; um contexto em que a barbárie é naturalizada.

Portanto, K.: relato de uma busca não é uma narrativa de um homem só, nem artisticamente e nem politicamente. É necessário que o leitor investigue os jogos de aparência, a realidade, as memórias, as violências e os crimes expostos pelos diferentes narradores. Mais que isso, é necessário desconfiar da veracidade dos discursos, contrapondo-os entre os personagens, pois o que Kucinski aparenta almejar não é um mero efeito estilístico, mas a representação de um movimento político de embate entre as vozes que aparecem no romance. Como visto, K.: relato de uma busca se sustenta pelo fio condutor da jornada de K. em busca de sua filha. No entanto, o percurso é atravessado por várias outras vozes, dos algozes e das vítimas. Dessa forma, o autor prevê a ampliação do entendimento do relato da ditadura, indicando que o mesmo fato histórico pode 
gerar outras narrativas diferentes. E essa variedade das narrativas possibilita outros pontos de vista que podem legitimar, contradizer ou deslegitimar a verdade histórica. A apresentação de determinadas vozes, outrora silenciadas e que agora tomam posição de definição dos atos a serem narrados, permite que sujeitos ilustrem as principais facetas constitutivas dessa narrativa ficcional a partir de um vínculo tão estreito com um importante evento da história brasileira.

Para K., a jornada pela busca de sua filha prenunciava as barbáries cometidas pelo governo militar, mesmo que de maneira não tão evidente. Como considera Lessa, ao indicar a existência de uma "dimensão complementar, as consequências afetam indiretamente aqueles que não são o alvo" $(2014,186)$. K. sente a ditadura. A violência mais brutal, de fato, só existia em suas memórias traumáticas de seu passado na Polônia. Já Jesuína se encontra no centro das relações de trapaça e em meio à brutalidade que toma forma nos porões da Casa da Morte. Desse modo, por serem vozes que não detinham a legitimidade do relato historiográfico tradicional, acabam por promover a possibilidade da reinterpretação dos fatos narrados por eles mesmos ou, no mínimo, uma versão diferente daquela já consagrada nos livros de história.

\section{Considerações finais}

Compreender, dessa forma, a manifestação dos narradores e das personagens, as várias possibilidades discursivas emitidas pelas variadas vozes e sua fragmentação, é igualmente compreender a estrutura narrativa de K.: relato de uma busca em suas especificidades. Percebemos como, especificamente no que diz respeito ao narrador que acompanha K., a linguagem narrativa empregada procura tentar nos convencer de que modo a ditadura também assassinou pessoas 
que continuaram vivas. Nesse mundo fronteiriço da ficção e da história, as múltiplas vozes servem para ressaltar as características fragmentárias e lacunares entre aparência e realidade, demonstrando como é perigoso cair no discurso fácil de uma história definitiva. $\mathrm{O}$ modo como se dá a jornada de K. está profundamente relacionado com o retrato inacabado da história, que é levado até as últimas consequências no romance, mas que é apenas um elo, de inúmeros outros, responsável pela afirmação de um curso que movimentou a sociedade brasileira e continua a reverberar até os dias de hoje.

A complexa tensão da relação entre as vozes no romance representa as inúmeras lutas, a violência como a expressão máxima do regime político, que teve início em 1964 com o avanço do conservadorismo, a tentativa de reproduzir o fascismo e os discursos políticos vazios amparados no mito da pátria. Portanto, um dos méritos de K.: relato de uma busca reside justamente na tentativa de mostrar a direção de uma determinada tendência do "desenvolvimento" da sociedade brasileira, por meio da figuração particular das vidas individuais das personagens inseridas nesse contexto. 


\section{Referências}

CAETANO, Paulo Roberto Barreto. “O entorno vário e fragmentado em K.: relato de uma busca, de Bernardo Kucinski”. Cadernos benjaminianos, $\mathrm{n}^{0}$ 10, pp.77-87, mai. 2016. Disponível em:<http://www.periodicos.letras.ufmg.br/index.php/ cadernosbenjaminianos/article/view/10257>. Acesso em: 19 de mar. de 2021.

FIGUEIREDO, Eurídice. A literatura como arquivo da ditadura brasileira. Rio de Janeiro: 7 letras, 2017.

FINAZZI-AGRÒ, Ettore. “(Des)memória e catástrofe: considerações sobre a literatura pós-golpe de 1964". Estudos de literatura brasileira contemporânea, $\mathrm{n}^{\circ}$ 43, pp. 179-190, jan./jun. 2014. Disponível em: https://periodicos.unb.br/index.php/estudos/article/view/9952. Acesso em: 19 de mar. de 2021.

GASPARI, Elio. A ditadura escancarada. Rio de Janeiro: Intrínseca, 2014.

KUCINSKI, Bernardo. K.: relato de uma busca. São Paulo: Companhia das Letras, 2016.

LESSA, Renato. "A experiência de K". In: K.: relato de uma busca. São Paulo: Cosac Naify, 2014.

LUKÁCS, György. O romance histórico. Tradução de Rubens Enderle. São Paulo: Boitempo, 2011. 


\title{
Resumo
}

A contemporaneidade é marcada por diversos discursos que, via de regra, marginalizam grupos minoritários, contribuindo para a perpetuação de vários ideais como únicos. Em obras literárias que possuem um nítido diálogo com a história, verificamos que essas múltiplas vozes, outrora silenciadas, passam a ganhar destaque, no romance contemporâneo, com o propósito de retomar e reelaborar acontecimentos passados e sua repercussão no presente. Em face de tais pressupostos, elegemos como corpus de análise o romance brasileiro K.: relato de uma busca (2016), de Bernardo Kucinski, com o objetivo de investigar e discutir as especificidades dos narradores, nessa forma literária particular, em sua estreita relação com a forma social, conciliando fenômeno literário e interpretação político-histórica. Esse objetivo é cumprido por meio da análise imanente do texto narrativo e do método materialista histórico-dialético. Como aporte teórico, recorremos às conceituações teóricas de romance histórico de György Lukács (2011) e às discussões de Figueiredo (2017), Lessa (2014), Caetano (2016), entre outros.

\section{Palavras-chave: múltiplas vozes; literatura contemporânea brasi- leira; ditadura brasileira; $K$.: relato de uma busca.}

\begin{abstract}
Contemporaneity is marked by several discourses that, as a rule, marginalize minority groups, contributing to the perpetuation of several ideals as the sole ones. In literary works that maintain a clear dialogue with history, these multiple voices, once silenced, start to gain prominence, in the contemporary novel, with the purpose of resuming and re-elaborating past events and their resonance in the present. In view of these assumptions, we chose as our corpus of analysis the Brazilian novel K.: relato de uma busca (K.: report of a search) (2016), by Bernardo Kucinski, in order to investigate and discuss the specificities of the narrators, in this particular literary form, in its close relationship with
\end{abstract}


the social form, reconciling literary phenomenon and political-historical interpretation. This objective is accomplished through the immanent analysis of the narrative text and the historical-dialectical materialist method. As a theoretical contribution, we use the theoretical concepts by György Lukács (2011) regarding the historical novel. The discussions conducted by Figueiredo (2017), Lessa (2014), Caetano (2016), among others, are also used.

Keywords: multiple voices; contemporary Brazilian literature; Brazilian dictatorship; K.: relato de uma busca. 